\title{
Design of Oral English Teaching Based on Embedded Microprocessor
}

\author{
Xiaojuan Yin \\ College of Foreign Languages, Minjiang University, Fuzhou 350108, Fujian, China \\ Correspondence should be addressed to Xiaojuan Yin; yinxiaojuan@mju.edu.cn
}

Received 16 December 2021; Revised 12 January 2022; Accepted 21 January 2022; Published 1 March 2022

Academic Editor: Haibin Lv

Copyright (c) 2022 Xiaojuan Yin. This is an open access article distributed under the Creative Commons Attribution License, which permits unrestricted use, distribution, and reproduction in any medium, provided the original work is properly cited.

Under the background of internationalization, China has put forward the strategy of "one belt and one road"; this puts forward higher requirements for the cultivation of internationalized and compound talents for English majors in China. However, through the investigation of the present situation of College Students' oral English teaching and their oral competence, it is found that college students' oral English competence and intercultural communication competence are generally low. The teaching concept is backward, the teaching mode is outdated, there are few opportunities for oral practice, and there is a lack of real communication environment. The level of teachers needs to be improved. The purpose of this paper was to design oral English teaching based on embedded microprocessor, aiming at the empirical research on the cultivation of College Students' intercultural communicative competence. This paper puts forward a teaching experiment scheme, which is guided by processor-based teaching method and guided by cultural teaching skills. Teaching skills refer to the stable and complex teaching behavior system formed by teachers using the existing teaching theoretical knowledge and practice. It includes both skills based on teaching theory and experience in practical use. In order to improve students' intercultural communicative competence through oral class and to verify the applicability of processor-based approach in oral English class of College English to improve students' intercultural communicative competence, this paper conducts a one-semester teaching experiment. Processor-based teaching method and traditional teaching method are used in the experiment. Through these two teaching methods, the standard deviations of test scores are 3.2 and 3.0, respectively. Embedded has become the most common application method for the intelligentization of electronic systems. In addition to setting up separate courses, embedded systems are the most widely used means in many practical aspects involved, such as course design, graduation design, graduate thesis, and other topics.

\section{Introduction}

With the continuous development of China's economy, various measures such as the "Belt and Road," "Maritime Silk Road," and "BRIC Countries" are being implemented continuously. The ties between countries in politics, economy, education technology, trade, and other aspects are getting closer and closer [1]. As the trend of internationalization continues to increase, exchanges between peoples of various countries are becoming more frequent. The current trend of economic globalization continues to strengthen ties, political multi-polarization has become a foregone conclusion, and cultural exchanges between countries are becoming more frequent. The concept of "global village" has begun to be accepted by more and more people. At the same time, frequent exchanges between countries make the demand for talents with certain crosscultural communication skills more and more urgent [2]. In order to better promote a healthy and orderly development of politics, economy, culture, and education in all aspects of the international community, more easy communication is required, and people are required to master English as a universal language in transnational communication [3]. At present, there are only 6 international languages, namely Chinese, English, French, Russian, Arabic, and Spanish. In addition to having certain requirements for people's English listening, speaking, reading, and writing skills, the most important thing is to not only ask people to learn the language but also to understand the various national and cultural contents behind the language [4]. However, 
combined with the current actual situation and its own teaching experience, the status of intercultural communication competence of college students is not high, and the level of intercultural communication ability of students does not meet the requirements of curriculum standards [5]. When communicating with foreigners, smooth and effective communication is not possible in most cases. The reasons are also diverse. In general, we have the following aspects: First, we live in a Chinese-speaking environment, do not have the opportunity to fully use foreign languages for communication, and lack good second language learning. The learning environment has an adverse effect on language learning. When the external environment has a strong oral atmosphere, it will naturally stimulate more people to participate in a conversation, and vice versa. The environment, to a certain extent, will affect students' ability to use spoken English and English language skills [6]. Secondly, the teacher's teaching methods, teaching strategies, and the design of classroom activities will also have an impact on the students' learning outcomes [7]. Third, students' learning interests, learning expectations, learning motivation, and other factors will also have an impact on the learning outcome [8]. Fourth, combined with the status of China's exam-oriented education, students, teachers, and parents are basically aligned with the scores, subjectively neglecting the cultivation of cross-cultural communication skills required for English subject learning [9]; The questions written, the content of the textbooks, the order setting, the writer's propensity, etc., all have an impact on the input of the classroom to the students [10].

Language is the unique symbolic information of culture and society. Culture is expressed through symbolic information. Cultural symbols refer to signs with certain special connotations or special meanings. They are the abstract embodiment of the unique culture of an enterprise, a region, a nation, or a country, and are an important carrier and form of cultural connotation. As an indispensable aspect of language teaching, cultural teaching has become more and more important in the era of global multicultural communication [11]. To truly master a language, one must understand the cultural meaning behind the target language and establish a multicultural thinking world [12]. Multiculturalism means that in the context of a more and more complex human society and more and more developed information circulation, the renewal and transformation of culture is also accelerating. The development of various cultures faces different opportunities and challenges, and new cultures will emerge one after another [13]. Learning a foreign cultural knowledge has a positive effect on the English language learner's language ability enhancement, which is a cumulative process [14]. English teaching exposes English learners to foreign cultures, which is conducive to the promotion of Chinese culture. It is also a way for them to learn the way of thinking and behavior in the context of the target language-the process of cultural communication [15]. English learners have a deeper and richer target language culture background, and their daily communication at work and study can be carried out more smoothly [16]. Aiming at the processor-based teaching mode itself, this research has sorted out the relevant theoretical system of the oral language teaching in the processor-based teaching mode, analyzes the impact of processor-based teaching mode on college oral English teaching, and proposes optimized teaching inspiration based on the existing teaching mode [17]. This is conducive for the development of processorbased teaching mode in college oral English teaching, and also provides theoretical and practical guidance for college English oral teaching [18].

Baldi et al. found evidence that processor-based training methods can improve the performance of children with handwriting difficulties. They studied and tested the power of the Handwritten Task Program (HTP). Three boys (9-10 years old) with poor handwriting skills and different developmental disabilities participated in HTP twice a week for 13 weeks. The handwriting accuracy was assessed by the Children's Handwriting Concise Assessment Scale and the written skills of children aged 7 to 13 were evaluated before and after visual processing integration tests and battery testing to assess fine motor performance and handwriting speed $[19,20]$. Although one child had some handwriting difficulties with developmental coordination disorder (DCD), the exercise efficiency and overall handwriting quality of all children improved. Further research may confirm that larger space-based training based on visual space may improve handwriting clarity in children with DCD [21]. Ni et al. found that appropriate activities that are closely related to daily life enable students to participate enthusiastically in these activities and improve their English listening skills. The study of processor-based listening teaching has significant significance in teaching theory and practice. They conducted an experiment in junior high school listening teaching to test whether students can improve their interest in learning English and improve their listening ability by adopting a "language-based approach" and explore the application of the best method theory in English listening teaching. Their experiment lasted for three months and involved two junior high school courses for 74 students. One is an experimental class that uses a processorbased approach in teaching, and the other is a control class that uses traditional teaching methods. There was no difference in the hearing of the students who participated in the experiment before the experiment. Their model mobilizes students' enthusiasm for English learning. Over time, teaching theory has guiding significance for students' English learning [22]. Abdellah A and his team looked at the whole history and found that Western language teaching has always relied on traditional methods, while traditional methods rely mainly on teachers as a source of language and cultural information. These methods are primarily limited to the teaching/learning of grammar and structure, and/or to native speakers of the language being studied/professed. To support this argument, his team used qualitative content analysis to capture evidence from the history book $\mathrm{Al}$ Muqqadimah by medieval Muslim thinker Ibn Khaldun. They found that medieval Muslim thinkers developed many teaching methods similar to modern teaching methods, and also provided language teaching for nonnative speakers [23]. 
The structure of this article is arranged in accordance with the general idea of the total score. In order to help students develop cross-cultural communication skills, this article proposes the application of embedded microprocessors in oral English classroom teaching. The most important part three and part four of this article introduces the application experiment of embedded microprocessor in college oral English classroom teaching. Through the current status of embedded teaching and the main content and significance of the research, it can be concluded that the application of embedded microprocessors in oral English classroom teaching can help students improve their oral English and intercultural communication skills.

\section{Proposed Method}

\subsection{Processor-Based Teaching Method}

2.1.1. Definition of Processor-Based Teaching Method. In the processor-based teaching mode, the main purpose of teaching is to achieve specific teaching effects while completing tasks; the main means of processor-based teaching mode is the design and implementation of "tasks." The processor-based teaching model mainly focuses on "tasks." The task of this paper is to improve the effect of oral English teaching. Therefore, the key to studying the processor-based teaching model is to define the tasks, that is, to figure out what tasks are. In a broad sense, tasks refer to activities that promote language learning, activities that are repeated in people's daily lives and work, and activities that achieve a communicative outcome. In a narrow sense, tasks are activities that have specific goals, specific content, specific contexts, and specific procedures in the English teaching process. To figure out what a task is, it should be made clear as to what is a processor-based teaching model. Therefore, in the processor-based teaching mode, the learner is guided by the teacher and focuses on the design and execution of the task. Teaching mode is a relatively stable teaching activity structure framework and activity procedure established under the guidance of certain teaching ideas or teaching theories. The hardware platform function is shown in Figure 1.

2.1.2. Characteristics of Processor-Based Teaching Methods. The main purpose of processor-based teaching is to improve learners' oral and practical communication skills. Its main features are:

(1) Highlight the centrality of the learner. "Taking students as the main body" is the biggest difference compared with the previous teaching mode. The processor-based teaching method emphasizes that students must have both autonomy and creativity in the learning process.

(2) Take the teacher as playing the leading role. Teachers play different roles by constantly changing roles in the course of the task, but the leading role of teachers is beyond doubt. Teachers should consider the students' background, needs, interests, and other factors when designing tasks. At the same time, the task is designed to make students realize the meaning of learning and gain something in the task.

Taking students as the main body refers to respecting the objective laws of students' learning in the learning process and not rushing for success, and taking teachers as the main body refers to giving full play to the ability of teachers to control the curriculum.

(3) Taking communication as the primary content. Language use is mostly based on communication in real life, so students should understand how to express in different environments and different objects. Processor-based teaching is to train students to use language knowledge in real life to complete daily communication.

\subsubsection{Teaching Mode of Processor-Based Teaching Method.} The teaching mode of the processor-based approach is designed to actively apply language knowledge to communication when the learner is tasking. Willis mode and Nunan mode are two popular task modes.

The Willis mode is divided into three phases: pre-task, task ring, and post-task. The pre-task stage: to prepare the task and establish the theme; the task cycle stage: the task implementation and completion; the post-task stage: summarize the results of the language practice. Unlike the Willis mode, the first step in the Nunan mode is to develop a number of pattern building exercises that will be used to introduce the topic, set the context of the task, and introduce students to some of the key words and expressions needed to complete the task; The second step is to provide students with controlled exercises using the vocabulary, structure, and function of the target language; the third step is to allow the learner to carry out intensive listening exercises. The textbook may involve many native speakers and ask questions about accommodation choices. The learner's task is to match the dialogue in the first step; The second step is to use the vocabulary of the target language; the third step is to have students perform intensive listening exercises; the fourth step is for students to participate in a series of exercises on one or more language elements; the fifth step is for students to practice more freely, beyond simple operations. They can be encouraged to use any language they can use to complete tasks on a temporary basis. At the same time, as learners "grow" into the target language, those who have a better understanding of the target language will become closer to native speakers. The design of oral English teaching is shown in Figure 2.

Although the two task modes have their own merits, no matter which model is based on students, it emphasizes the leading role of teachers in design tasks. At the same time, the implementation of tasks must be completed through interaction and cooperation to improve the communicative ability of learners. 


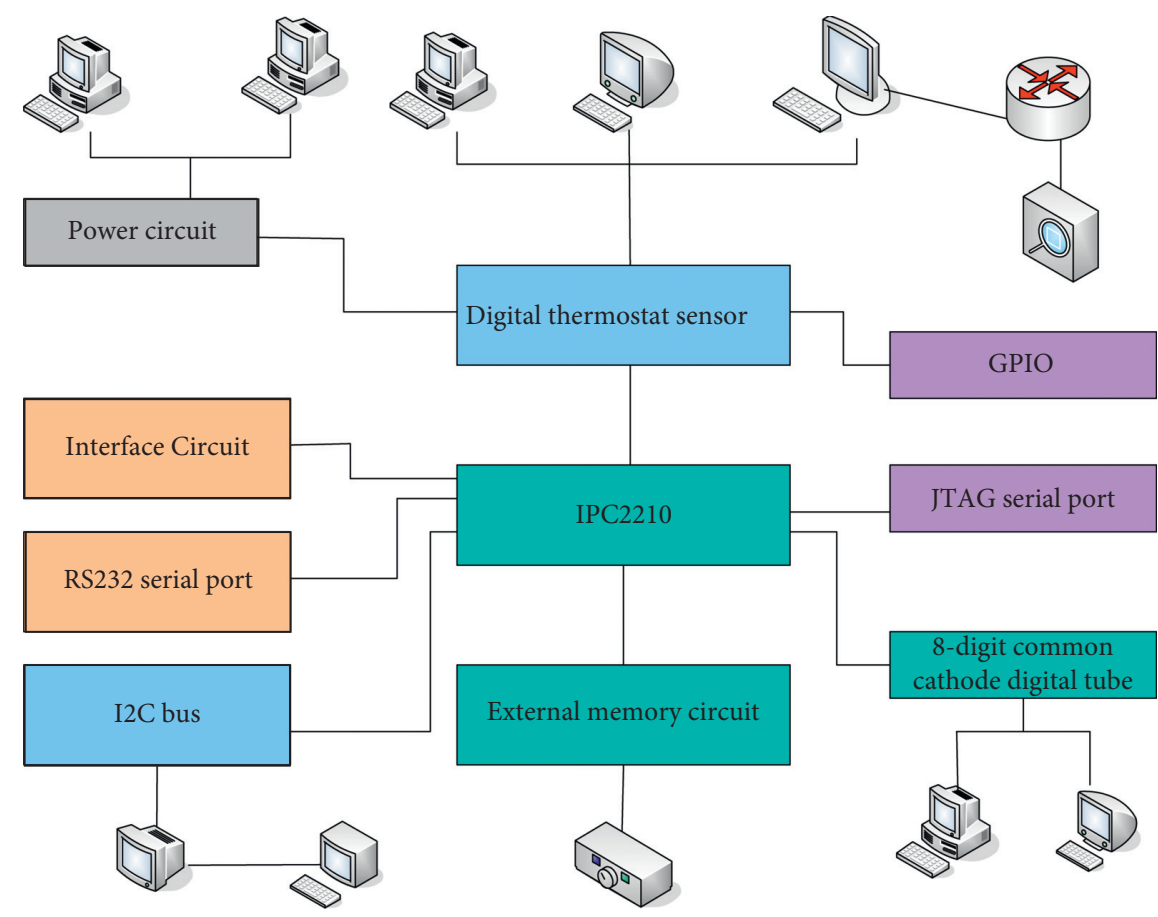

FIGURE 1: The hardware platform function.

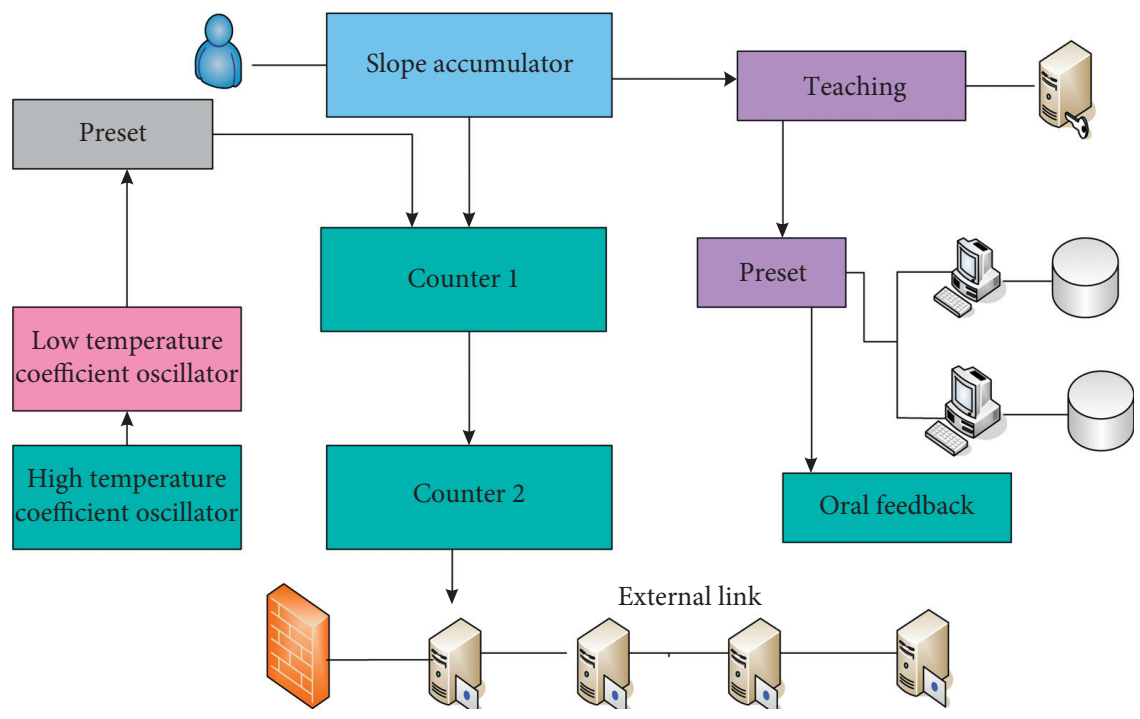

Figure 2: The design of oral English teaching.

$Q=\phi_{i j} \sum_{i=1} D^{2}$

$\mathrm{M}=\phi\left(1-\frac{\sum D}{D}\right)$

$Z=W * \mu$,

$H=\frac{Y-\bar{Y}}{\beta} \lambda$.
2.1.4. Application of Processor-Based Teaching Method in College Oral English Teaching. The teaching principles of processor-based college English oral classes are as follows:

(1) The principle of authenticity: The main purpose of oral teaching is to realize the communication of learners in daily life. The main feature of processorbased teaching method is also to emphasize communication as the primary content of teaching.. Therefore, teachers should not be bound by books when designing the tasks of college oral English 
courses, but need to consider the actual function of language and grasp the nature of oral English teaching. Teachers should design tasks that can achieve communication and interaction after considering the background, characteristics, and needs of the class students. In the process of carrying out tasks, learners can learn new language knowledge and know how to use it. This is completely different from the "sentence pattern" and "complete fill-inthe-blank" in traditional teaching. However, the principle of authenticity of the task cannot be completely separated from the syllabus. It only designs the real context for the knowledge point, and creates a communication platform that the learner can drill and use as much as possible to broaden the learner's way of thinking, so as to improve learners' language expression and comprehensive application skills.

$$
\begin{aligned}
Q & =[\beta+(1-R \lambda) M] \kappa, \\
\phi & =\sum_{i=1}^{M} \frac{M(R-T) F}{E}, \\
M & =\sum_{i=1}^{m}(P+Q) .
\end{aligned}
$$

(2) The principle of meaning priority: the principle of meaning priority can best reflect the teaching purpose of college oral English class. If the emphasis on language form in college oral English teaching hinders the absorption of language meaning, it is contrary to the original intention of oral teaching. The processor-based approach emphasizes that learners should pay attention to communication and interaction in the real environment, rather than mechanical training, in the process of completing tasks. Therefore, the principle of meaning priority in processor-based oral English teaching emphasizes that teachers and learners should pay attention to the expression of language meaning rather than form. Under the guidance of this principle, students can understand the language knowledge they have assimilated, and can feel the relationship between language form and function when completing tasks, thus improving the learner's ability to understand and express.

(3) The principle of interactivity: Both oral English and processor-based teaching emphasize the importance of the principle of interaction. The interaction mentioned here is not only the interaction between teachers and students but also the interaction between students in the task. The principle of interactivity focuses on the process of language input and output for students in their tasks. We can find in the oral class teaching that interaction is one of the best test methods to accelerate the harmonious relationship between teachers and students, the timely feedback of knowledge mastery, and the success of task design. During the course of the task, students exchange knowledge to digest what they have learned and become familiar with and use language skills. Therefore, interactivity is an indispensable principle of follow-up in processor-based oral English teaching.

2.2. Cultural Teaching Method. Cultural teaching in foreign language teaching is not as new as some foreign language teachers think. A review of culture in language teaching shows that before the 1960s, many educators began to pay attention to the importance of culture in foreign language learning. They considered ways to integrate culture into language teaching. In the early learning of the "culture of capital C" to better understand literary works, culture as a background knowledge was introduced into the students, and has little to do with language acquisition. The 1960 s and 1970s were also the peak of language teaching. A three-stage cultural teaching model has been proposed in which learners first "learn" cultural differences through language learning and practice, and then explore the foundations of formal and deep culture. The third stage is that learners accept cultural fullness, and systematically teach.

It was not until the 1980s that scholars began to explore the dynamics of culture and their important contributions to effective language learning. They believe that students should have an understanding of the basic information that is necessary to understand most cultural concepts. Regardless of who the planners are, they believe that the formal and informal aspects of the target culture should be reflected in the curriculum at all levels, such as understanding people's daily lives, their social institutions, their art and literature, their attitudes, and priorities.

In the 1990s, culture played a very important role in foreign language teaching. Among them, educators emphasized how to improve learners' social and cultural competence and intercultural communication skills. There are five aspects of theory that are inseparable because they interact with each other. The five areas include specific context, communicator appropriateness, effectiveness, knowledge blocks, and attentional factors.

Obviously, the role of cultural teaching in foreign language classrooms has attracted the attention of many teachers and scholars, and has caused considerable controversy. So far, there are two main points that influence cultural teaching: one involves facts, the other included dissemination of cultural information, including products, involving target civilizations, such as literature and art, customs and habits; using cross-cultural psychology or another anthropology, the idea is to embed culture within an interpretive framework and to establish a link between one's own culture and the target culture. Both methods have limitations because they only provide cultural knowledge to learners. How to cultivate learners' intercultural competence and understanding cultural knowledge has become an important topic. 


\subsection{Oral English Teaching and Intercultural Communication Competence}

2.3.1. Definition of Intercultural Communication Ability. The concept of intercultural communicative competence emerged in the early 1980s. Later, scholars from different disciplines and backgrounds conducted extensive research and discussion on this concept. The definition of intercultural communicative competence is summarized as follows:

(1) This ability is an internal ability, and intercultural communication ability is the ability within each individual. It is the ability of the individual's inner mental system to change its existing attributes and structure to suit the needs of the environment;

(2) This ability is a compound ability that is expressed as appropriate when a person interacts with a different person from his or her own language and culture. Social skills. Intercultural communicative competence is a collection of attitudes, methods, special behaviors, and reflective abilities that promote integration in a cross-cultural context. Four aspects of intercultural communication skills: understanding, knowing how, knowing why, understanding yourself; The composite competence referred to in the text refers to the tolerance and acceptance of diverse cultures.

(3) This ability is an adaptive ability. Intercultural ability helps to change one's own knowledge, attitudes, and behaviors in order to adapt to other cultures openly and flexibly. It has become a key to the 21st global society;

(4) This ability is an effective execution and behavioral ability. It refers to the ability of a person to be able to perform adequately and flexibly in the face of actions, attitudes, and expectations of foreign cultural representatives. Intercultural communicative competence is the ability to effectively and appropriately perform communication behaviors that lead to the desired response in a particular environment;

(5) This ability is a viability. Intercultural communicative competence refers to the ability to create a comfortable third-party position between one's native language culture and the target language culture.

2.3.2. The Importance, Component, Classification, Function of Intercultural Communicative Competence, and the Relationship between Foreign Language Teaching and Intercultural Communication Competence.

(1) In terms of the components of intercultural communication competence, foreign language teaching objectives can be divided into three dimensions: language ability, communicative ability, and social cultural ability. Broadly speaking, the ultimate goal of English teaching is to cultivate social and cultural abilities. This refers to the ability to use existing knowledge to effectively process social and cultural information.
(2) In terms of the role of intercultural communication competence, intercultural communication competence is a lubricant that can make some difficult problems easier to solve. It can make it possible to do the impossible. How to improve the intercultural communication competence through the combination of cultural knowledge and language skills is an urgent problem we need to solve. In terms of the importance of this ability, the main task of second language teaching is to develop students' intercultural communication skills.

(4) In terms of the relationship between foreign language teaching and intercultural communication competence development, the ultimate goal of cultural learning and language learning is to understand more cultural groups, master common rules of intercultural communication, improve intercultural awareness, and improve intercultural communication skills. Being able to conduct intercultural communication, and ultimately strive to become a successful intercultural communicator, it is necessary to cultivate a person's intercultural communication competence to focus on training from three levels of knowledge, behavior, and attitude.

$$
\begin{aligned}
\operatorname{sim}\left(R, M^{\prime}\right) & =\sum_{m=1}^{n} G M * \operatorname{sim} R\left(M, N^{\prime}\right), \\
\operatorname{sim} P\left(c_{1}, c_{2}\right) & =\phi \lambda, \\
R\left(M_{1}, M_{2}\right) & =\frac{\left\|M_{1}-M_{2}\right\|}{\left|M_{1}\right|} \\
U\left(F_{1}, N_{2}\right) & =\sum_{i=1}^{n} F_{j} \cdot U\left(F_{1}, N_{2}\right) .
\end{aligned}
$$

2.3.3. The Function of Intercultural Communication Ability. The study analyzes the cross-cultural communication literacy and finds that this subject can be divided into two types, namely, maintenance and behavioral cultivation. Thinking about maintenance refers to the ability of intercultural communication to achieve individual adaptation to different cultures; behavioral cultivation refers to the ability to communicate across cultures in specific situations.

(1) Ways of thinking

The way of thinking cultivation refers to the individual proficiency of intercultural skills, that is, the ability to initiate intercultural communication, knowledge of different cultures, skills to accomplish goals, and good character. Secondly, the cultivation of thinking style also means that people can predict and overcome potential cross-cultural issues, including feelings of anxiety and hesitation, perceptions of prejudice, national superiority, and cultural shock. Understanding cultural differences and being willing to accept them is part of the cultural adaptation process. The theory of cultural adaptation 
helps to understand the challenges of accepting cultural differences and the characteristics of resistance and acceptance over time.

$$
\begin{aligned}
N(s, p) & =\max \left(N\left(M, N_{i}\right) \mid M \in p\right), \\
A\left(P_{1}, P_{2}\right) & =\frac{\sum T\left(H, M_{1}\right)+\sum T\left(H, M_{2}\right)}{V_{1}+V_{2}}, \\
G & =U_{i=1}^{M}(J(E F)), \\
G(N) & =U_{i=1}^{m}(F(N)) .
\end{aligned}
$$

(2) Cultivation of cultural behaviors and communication skills

People's communication always takes place in externally influenced situations, so any communicative phenomenon is formed by cultural, social, and material factors. In addition, all communication situations require communicators to follow appropriate communication rules, so cross-cultural communicators are important to sense the formality of interpersonal situations, interpersonal harmony, and the appropriate relationship between people.

$$
\begin{aligned}
G & =\left(G_{1}, G_{2}, \ldots, G_{n}\right), \\
W(B) & =\left(\amalg T_{1}\left(B_{1}\right), \amalg T_{2}\left(B_{2}\right), \ldots, \amalg T_{N}\left(B_{N}\right)\right), \\
V_{\mathrm{QC}} & =V_{P} \cup V_{T} \cup V_{O}, \\
V_{\mathrm{QC}} & , V_{P}, V_{T}, V_{O} \text { indicate different evaluation criteria. }
\end{aligned}
$$

This paper studies the cross-cultural communication situation of second language education. In the context of second language education, intercultural communication represents two aspects. The first aspect is that teachers and students are essentially involved in cross-cultural communication. Teachers need to pay attention to the characteristics and differences of students' cultural backgrounds. In the case of multiculturalism, it may be more challenging, because teachers should also pay attention to the differences in their educational methods, such as relationships, interactions, cognition, and motivation, which may create cultural conflicts in teaching. On the other hand, the content of the second language course aims to increase the cultural awareness of the student' target language, which means that students accept the cultivation of intercultural communication skills, and the second language teachers become proficient cross-cultural communicators. When the cultural background between students is the same, teachers may encounter the challenge of racial centralism. Students desire to maintain their cultural identity, but in the third space, the second language classroom becomes a place of cultural contradiction. Cultural atmosphere sometimes exists in the language and cultural environment of the destination and sometimes in the student's native language culture. Therefore, second language teachers should create a relatively safe teaching environment and allow second language learners to adapt to new cultural norms.

$$
\begin{aligned}
J \mathrm{~K} & =\lambda\left(J K_{Q C}-J K_{e f}\right), \\
Q_{Q} & =Q_{R}+Q_{M}+Q_{P}+Q_{O}, \\
\vec{C} & =\left\{C_{1}, C_{2}, C_{3}, C_{M}\right\},
\end{aligned}
$$

$\vec{C}$ Is a vector parameter.

\section{Experiments}

3.1. Experimental Object. The subjects were 103 non-English majors at the university. The experiment time was from February 26 to June 21, 2019 (one semester). They were divided into two groups: the experimental group (50 students) and the control group (53 students). One class group used the processor-based teaching method to teach, while the other class used the traditional teaching method to teach. The teaching content is the New Vision College English Course Book 2, Units 1-10, published by the Foreign Language Teaching and Research Press. As a control, there was no difference in their English speaking ability based on previous test scores before the experiment. The author of this article uses processor-based instruction for the experimental group. During the experiment, a normal teaching order was maintained to avoid an atmosphere of human competition. The GPIO registers are shown in Table 1.

3.2. Experimental Methods. Teaching procedures include: pre-task settings (preliminary activity, task introduction), task completion (practice, report), focus (teacher feedback, analysis, and discussion), and sequencing work (student's experiential learning). Each register in the timer is shown in Table 2.

In order to meet the requirements, a variety of teaching methods have been adopted in the teaching process:

(1) Processor-based teaching methods: pre-task activities (introduction and setting tasks), core activities (reports, discussions, and oral reports), support activities (problem solving, participation, and group interaction), teacher feedback, and assessment.

(2) Cultural methods: comparison, comparison, video, role playing, case study.

(3) Traditional teaching methods: speech, listening, consolidation, and homework. In the article, R1 and $\mathrm{R} 0$ are used to set the resolution, as shown in Table 3.

3.3. Experimental Steps. Based on the processor-based language teaching framework cited above by Willis and Nunan, this study proposes a five-step model of processorbased language teaching in oral English: task demonstration, control exercises, reporting, analysis and teacher feedback, and topic debate. The ROM operation instructions in the article are shown in Table 4.

Step 1: The teacher teaches by introducing the actual language sample to the task. These language samples are presented through dialogue or movie clips. The teacher 
TABLE 1: The GPIO registers.

\begin{tabular}{lcc}
\hline Name & Address & Describe \\
\hline IOPIN & 0xE0028000 & Pin value register, the current state of the pin is read from this register \\
IOSET & 0xE0028004 & Output setting register, only I can be written, and the corresponding pin outputs are high level \\
IOCLR & 0xE0028008 & Output clear register, can only write 1, and the corresponding pin outputs are low level \\
IODIR & 0xE0028000 & Direction control register to control the direction of each I/O \\
\hline
\end{tabular}

TABLE 2: Each register in the timer.

\begin{tabular}{llc}
\hline IR & Address & Describe \\
\hline 0 & MR0 interrupt & Match the interrupt flag of channel 0 \\
1 & MR1 interrupt & Match the interrupt flag of channel 1 \\
2 & MR2 interrupt & Match the interrupt flag of channel 2 \\
3 & MR3 interrupt & Match the interrupt flag of channel 3 \\
4 & MR4 interrupt & Match the interrupt flag of channel 4 \\
5 & MR5interrupt & Match the interrupt flag of channel 5 \\
\hline
\end{tabular}

TABLE 3: R1 and R0 are used to set the resolution.

\begin{tabular}{lccc}
\hline R1 & R0 & Temperature resolution & Maximum conversion time (ms) \\
\hline 0 & 0 & 9 & 50 \\
0 & 1 & 10 & 100 \\
1 & 0 & 11 & 150 \\
1 & 1 & 12 & 170 \\
\hline
\end{tabular}

TABLE 4: The ROM operation instructions in the article.

\begin{tabular}{lcc}
\hline Number & Instruction & Illustrate \\
\hline 1 & 55 & Specify matching chip instruction \\
2 & CC & Skip ROM matching instructions \\
3 & FO & Search chip instructions \\
4 & EC & Alarm chip search \\
\hline
\end{tabular}

should ensure that the students understand the task guide.

Step 2: Students should practice using target language expressions and functions in a simulated situation.

Step 3: Ask students to report their views on the controlled exercises in the second step. Sometimes, some teams are asked to show their reports to the class.

Step 4: Comment and analyze the content, organization, and communication of the report. This step provides an opportunity for the whole class to take the initiative to speak.

Step 5: After discussing the topic individually or in groups, ask the students to give a short speech to comment on the cultural dialogue.

3.4. Experimental Implementation. The first part of the test paper consists of ten cases, each with four statements. The test paper includes the following items: greetings, ability to analyze cultural differences, encouragement, customs, praise, eating habits, and departure. The second part consists of five scenarios designed to determine the level of intercultural communicative competence that participants demonstrate when objectively responding to cross-cultural situations that require effective and appropriate behavior. In order to minimize the bias involved in self-reporting of predictive behavior, participants are asked to express their opinion on what should be done in one of the roles in the situation rather than what should be done in that situation. These scenarios require participants to respond to situations that require both specific behavior and general behavior. To ensure the authenticity, reliability, and effectiveness of the test, the cultural test was taken as part of the final exam on June 25, 2019.103 test papers were distributed during the test and collected. The score statistics information is shown in Table 5 .

\section{Discussion}

\subsection{Analysis of Cultural Test Scores.}

(1) For the experimental group, the average value of the culture test score was 14.8. The highest score was 32 and the lowest score was 2 . The results of the experimental group are shown in Figure 3:

(2) The experimental group has a score of 30 and the standard deviation is calculated as 3.2. In terms of dispersion, these two numbers show a broad distribution of scores. Since the purpose of the test is to determine the extent to which students can analyze cultural differences in the target culture, the standard deviation of 6.4 indicates that a fairly broad spread will be satisfactory. The discrimination of the entire sample is 0.6 , which is a fairly high index. That is to say, the test project clearly distinguishes the students to be tested, thus distinguishing students with stronger ability from those with weaker ability. As for the difficulty, 0.15 is a very low index. After the entire semester of cultural teaching, the test group students 
TABLE 5: The score statistics information.

\begin{tabular}{lcc}
\hline Chinese name & English name & Type of data \\
\hline Grade number & Score_ID & Numeric $(9,0)$ \\
Teacher ID & Tea_ ID & Varchar $(10)$ \\
Read aloud & LD & Smallint $(2)$ \\
Question 1 & WD1 & Smallint (2) \\
Question 2 & WD3 & Smallint (2) \\
\hline
\end{tabular}

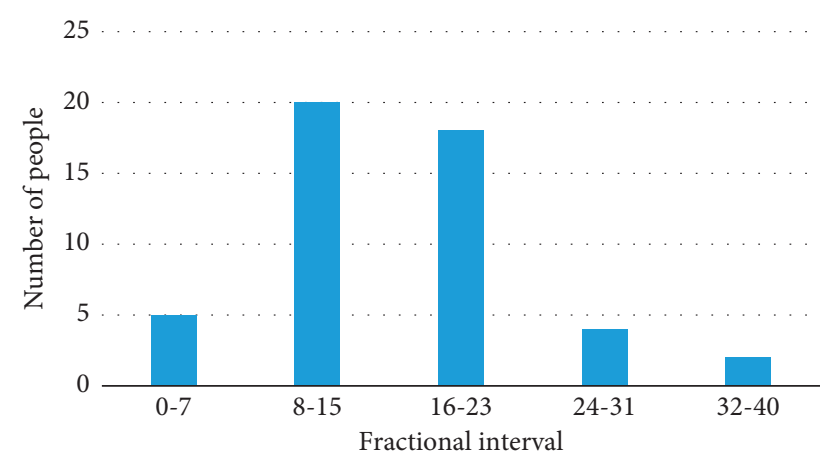

Figure 3: Score distribution of the experimental group.

showed great differences in their academic performance. The results of the experimental group are shown in Figure 4:

(3) The situation in the control group is quite different. The highest score was 30 , the lowest score was 2 , and the average was 5.61. The distribution of the results of the control group is shown in Figure 5:

(4) The standard deviation of the control group was 3.0. Since the average score is low, the number of deviations is far from satisfactory. The sample discrimination is as low as 0.35 , which means that the subjects are not as clearly separated as their language level. The results of the control group is shown in Figure 6:

The statistical data showed a sharp contrast between the two groups, with the experimental group having a higher score than the control group. One-semester experimental teaching has a great influence on students' ability to distinguish culture. The system information is shown in Table 6.

4.2. Recorded Oral Test Score Analysis. The oral exam consists of three parts, including reading aloud, answering questions within five words, and topic discussion. The total score of the question is fifteen points. Five English teachers sat together to score each record, and the average of the scores given by the five teachers was the individual's final score. The test content did not exceed the theme of the New Vision College English Course Book 2, which aimed to measure the mastery of the students' of the teaching materials. The experimental group was the first group and the control group was the second group. The comparison between the two groups is shown in Table 7 and Figure 7:

It can be seen from Table 7 and Figure 7 that the results between the two groups are slightly different. This means that the scores of the first group are slightly higher than the

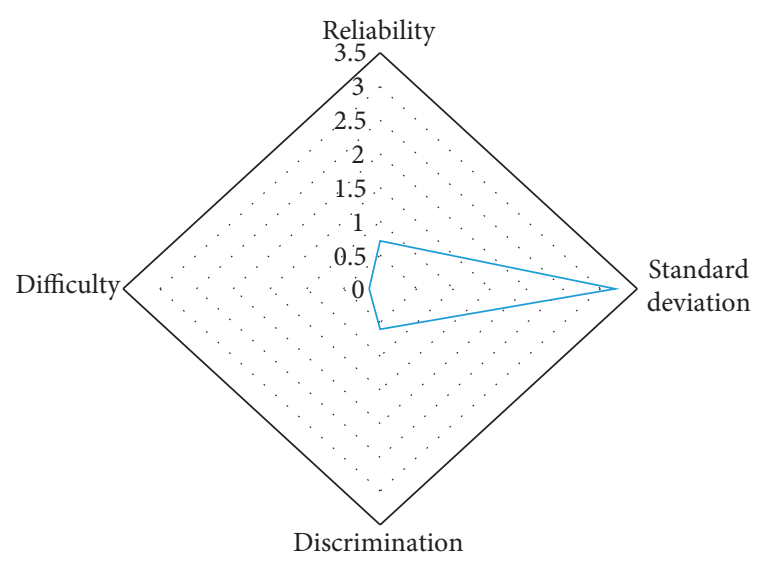

Figure 4: Analysis of the results of the experimental group.

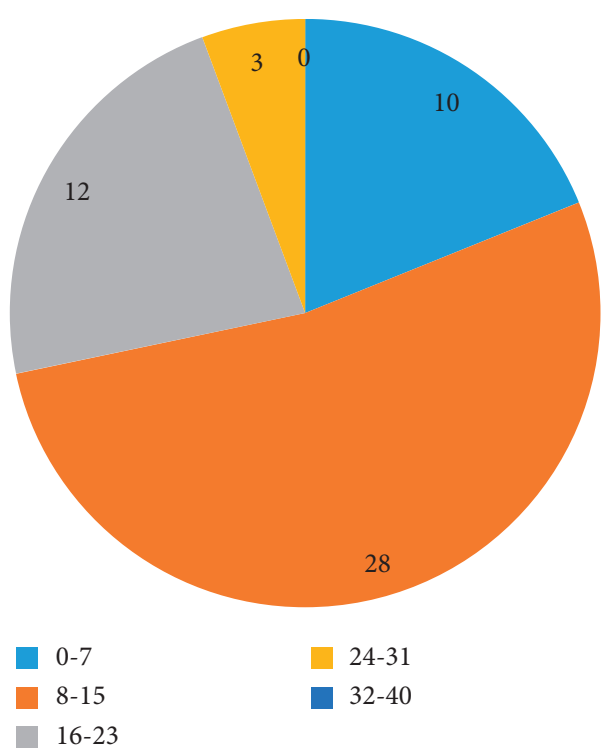

FIgURE 5: Distribution of scores in the control group.

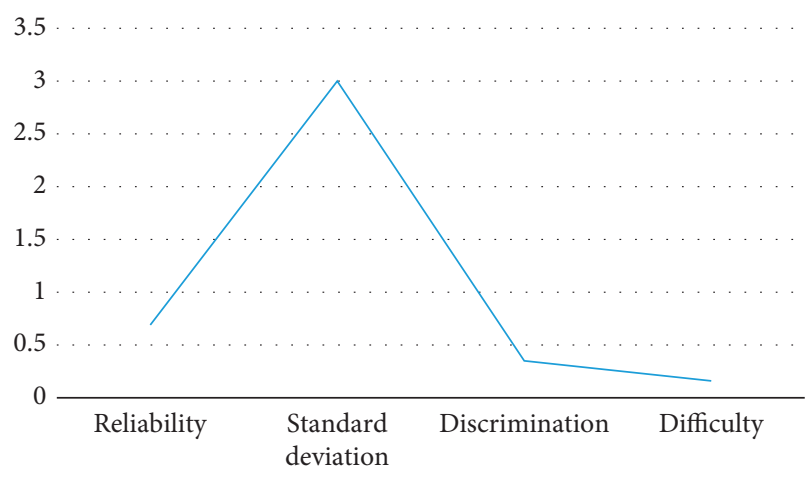

FIgUre 6: Analysis of the results of the control group.

second group, and can partially explain the correlation between cultural competence and language ability. In other words, attempts to develop intercultural communicative competence in accordance with established methods will have a positive impact on students' language skills. The obtained SQL Server database is shown in Table 8. 
TABLE 6: The system information.

\begin{tabular}{lcc}
\hline Chinese name & English name & Type of data \\
\hline Administrator username & AdminName & Varchar (50) \\
Administrator password & AdminPWD & Varchar (50) \\
Secondary login password & ReExamPWD & Varchar (50) \\
Query results & StuChaXun & Char (1) \\
Open the marking system & TeaPingFen & Char (1) \\
Home information & Message & Varchar (100) \\
\hline
\end{tabular}

TABle 7: Score comparison table.

\begin{tabular}{lccccc}
\hline & Group 1 & Group 2 & & Group 1 & Group 2 \\
\hline Number of testers & 50 & 53 & Difficulty & 0.57 & 0.63 \\
Highest score & 13.5 & 13.5 & Reliability & 0.75 & 0.69 \\
Lowest score & 4.2 & 3 & Discrimination & 0.46 & 0.66 \\
Mean score & 11.2 & 11 & Standard deviation & 2.5 & 2.3 \\
\hline
\end{tabular}

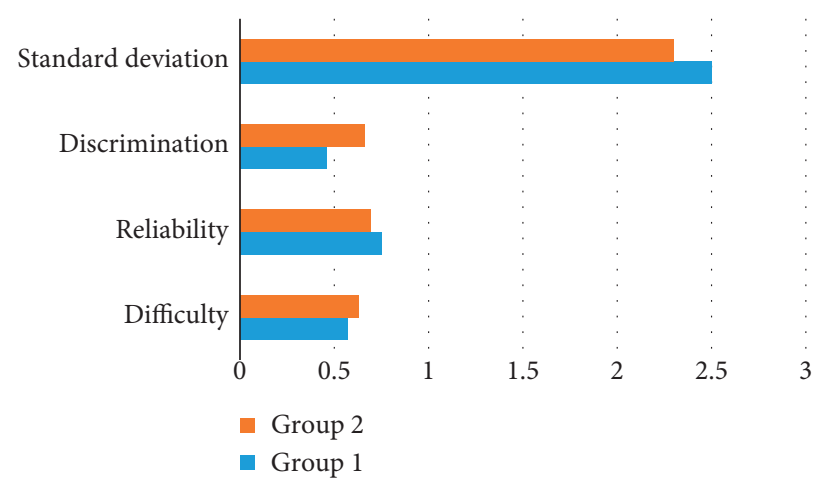

Figure 7: Analysis of the scores of the two groups.

TABLE 8: The obtained SQL server database.

\begin{tabular}{lcr}
\hline Chinese name & English name & Type of data \\
\hline Teacher ID & TEA_ID & Varchar (10) \\
Name & name & Varchar (50) \\
Gender & Sex & Varchar (2) \\
Login password & PWD & Varchar (50) \\
Job title & ZhiCheng & Varchar (10) \\
\hline
\end{tabular}

Most students completed the questionnaire with a serious attitude. The results of the student questionnaire are shown in Table 9.

The male teachers interviewed this time accounted for $13.33 \%$, and the female teachers accounted for $86.67 \%$. The number of interviewed invitations is shown in Figure 8.

The interviewed teachers are mainly young and middleaged teachers, all of whom have certain teaching experience. $46.67 \%$ are under 30 years old, $33.33 \%$ are between 30 and 40 years old, and only $20 \%$ are over 40 years old. The age distribution is shown in Figure 9.

The evaluation in terms of job title evaluation is shown in Figure 10. $6.67 \%$ of teachers have senior professional titles, $20 \%$ have first-level professional titles, 53.33\% have second-level professional titles, and $20 \%$ are junior teachers.

The survey of teachers' oral English teaching is shown in Figure 11.
Before the experiment, the differences in the initial oral scores of the two groups of students were tested. The results are shown in Table 10. The average score of the experimental class was 5.529 and the control class was 5.011.

The students' oral level should be gradually improved in accordance with the objective development law, but the post-test results of this experiment are generally lower than the pre-test results. This is because the overall difficulty coefficient of the Haiyuntian human-computer dialogue test questions is quite similar, but the listening questions in the post-test questions are relatively simple and spoken. The average score is shown in Table 11.

The total reliability coefficient of the scale is 0.894 , which are all above 0.7 , indicating that the reliability of this survey questionnaire is very high. The results of the scale reliability test are shown in Table 12.

The validity of the scale is tested by the public variance value, and the common factor analysis of variance of the 
TABLe 9: The results of the student questionnaire.

\begin{tabular}{lcc}
\hline Project & Number of people & Percentage \\
\hline (1) Like to take English class & 289 & 7225 \\
(2) Speaking is more important than listening, reading, and writing & 239 & 59.75 \\
(3) In class, worry about being spoken poorly by others & 202 & 50.5 \\
(4) Make fun of & 123 & 30.75 \\
(5) Able to answer questions in English fluently & 236 & 59 \\
\hline
\end{tabular}

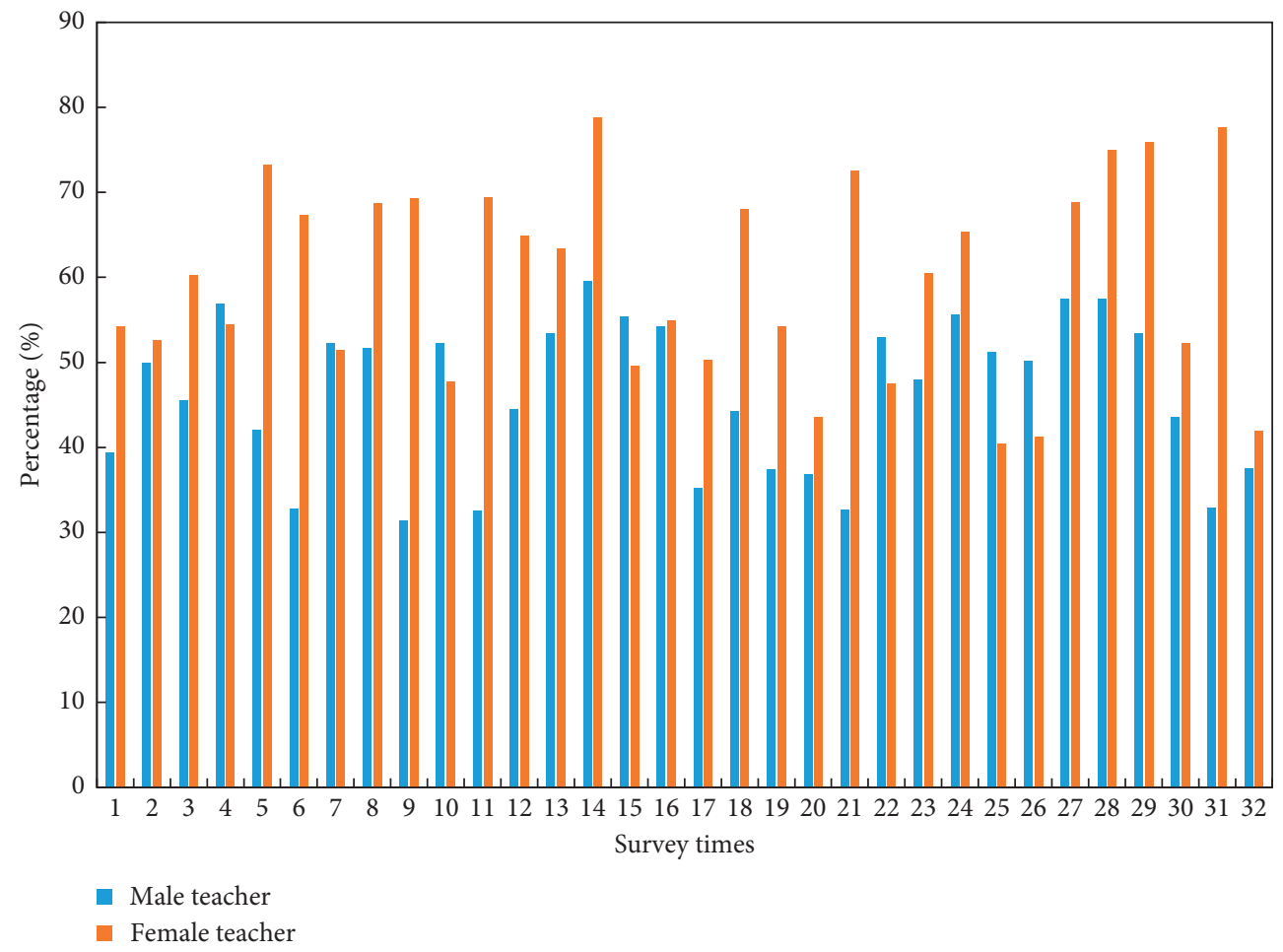

Figure 8: The number of interviewed invitations.

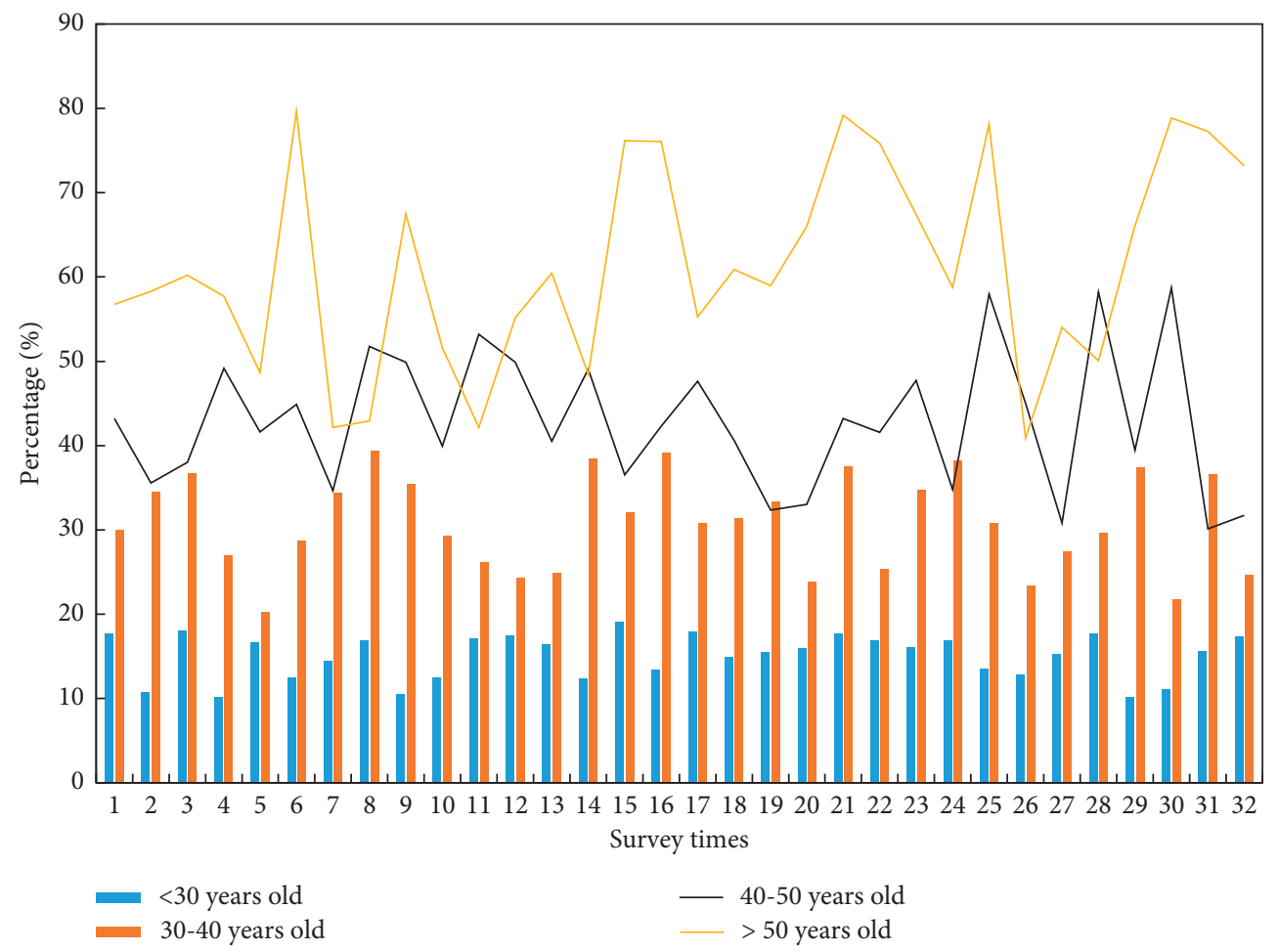

FIgURE 9: The age distribution. 


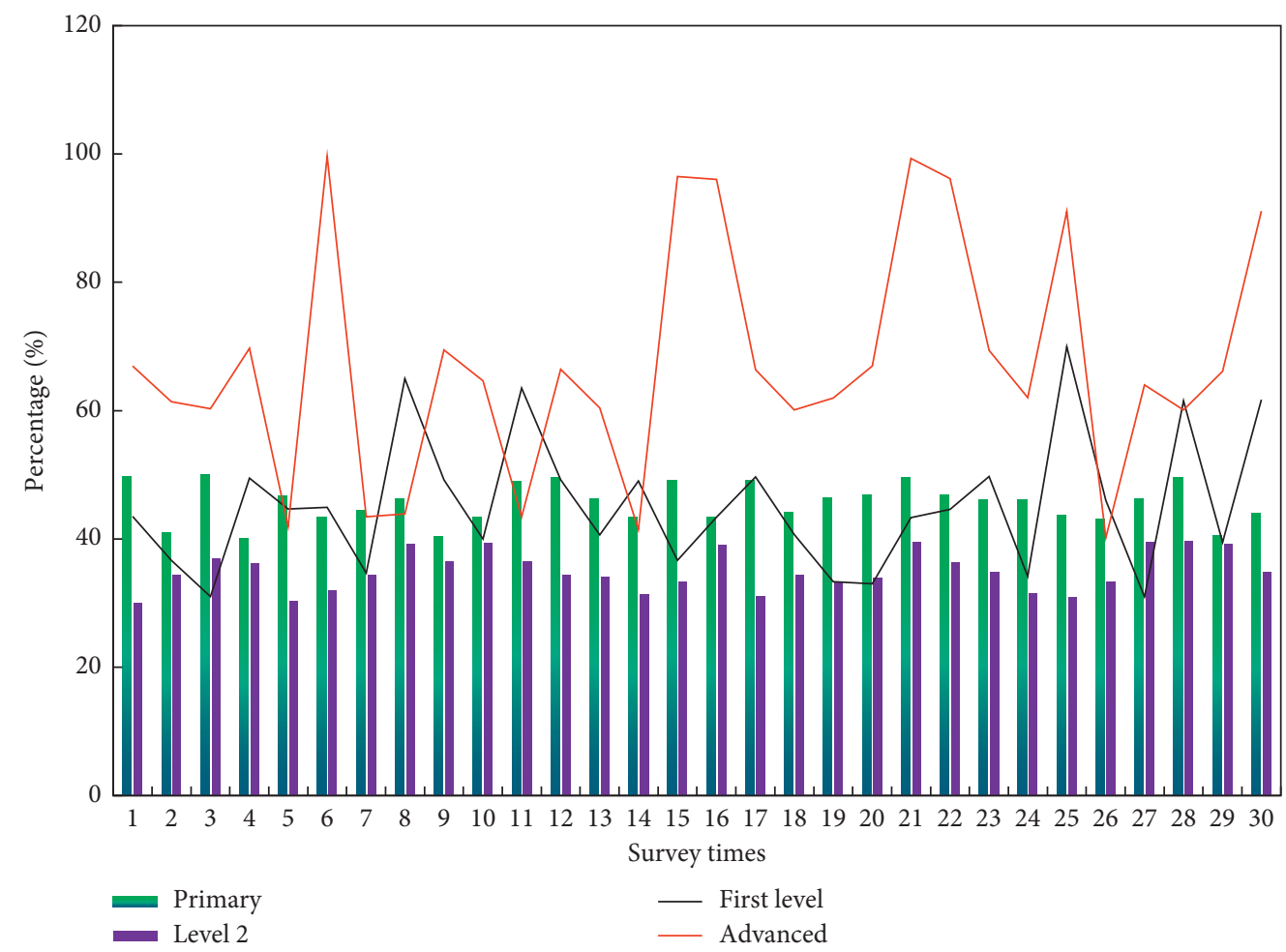

FIgURE 10: The evaluation in terms of job title evaluation.

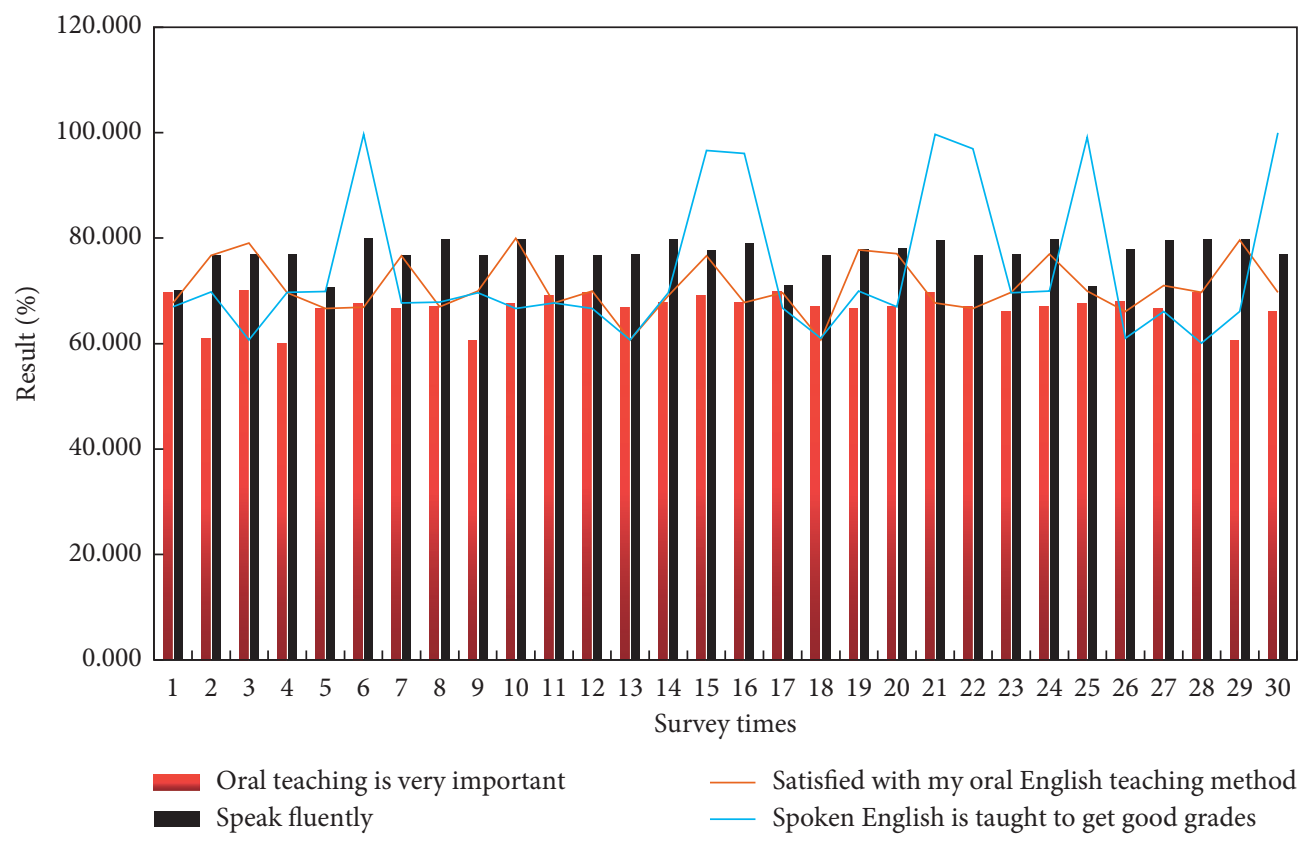

Figure 11: The survey of teachers' oral English teaching.

TABLE 10: The differences in the initial oral scores of the two groups of students were tested.

\begin{tabular}{lcccc}
\hline Parameter & Class & Number of cases & Average value & Standard deviation \\
\hline \multirow{2}{*}{ Oral score } & Experimental class & 35 & 5.529 & 1.4606 \\
& Control class & 35 & 5.011 & 1.6588 \\
\hline
\end{tabular}


TABLE 11: The average score.

\begin{tabular}{lccc}
\hline Project & Class & Number of cases & Average value \\
\hline \multirow{2}{*}{ Read short essays } & Experimental class & 35 & 2.451 \\
& Control class & 35 & 2.257 \\
Situational question and answer & Experimental class & 35 & 1.000 \\
& Control class & 35 & 0.889 \\
Topic brief & Experimental class & 35 & 1.677 \\
& Control class & 35 & 0.963 \\
\hline
\end{tabular}

TABLE 12: The results of the scale reliability test.

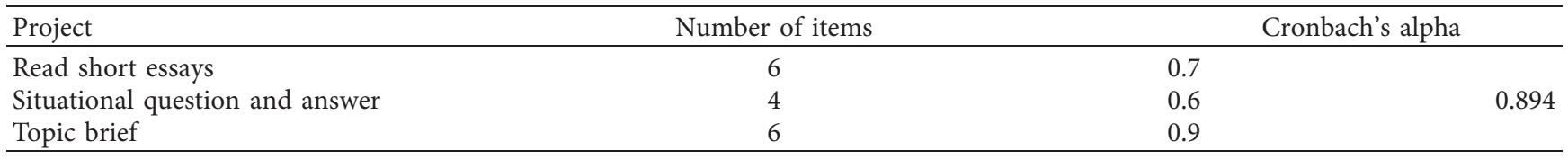

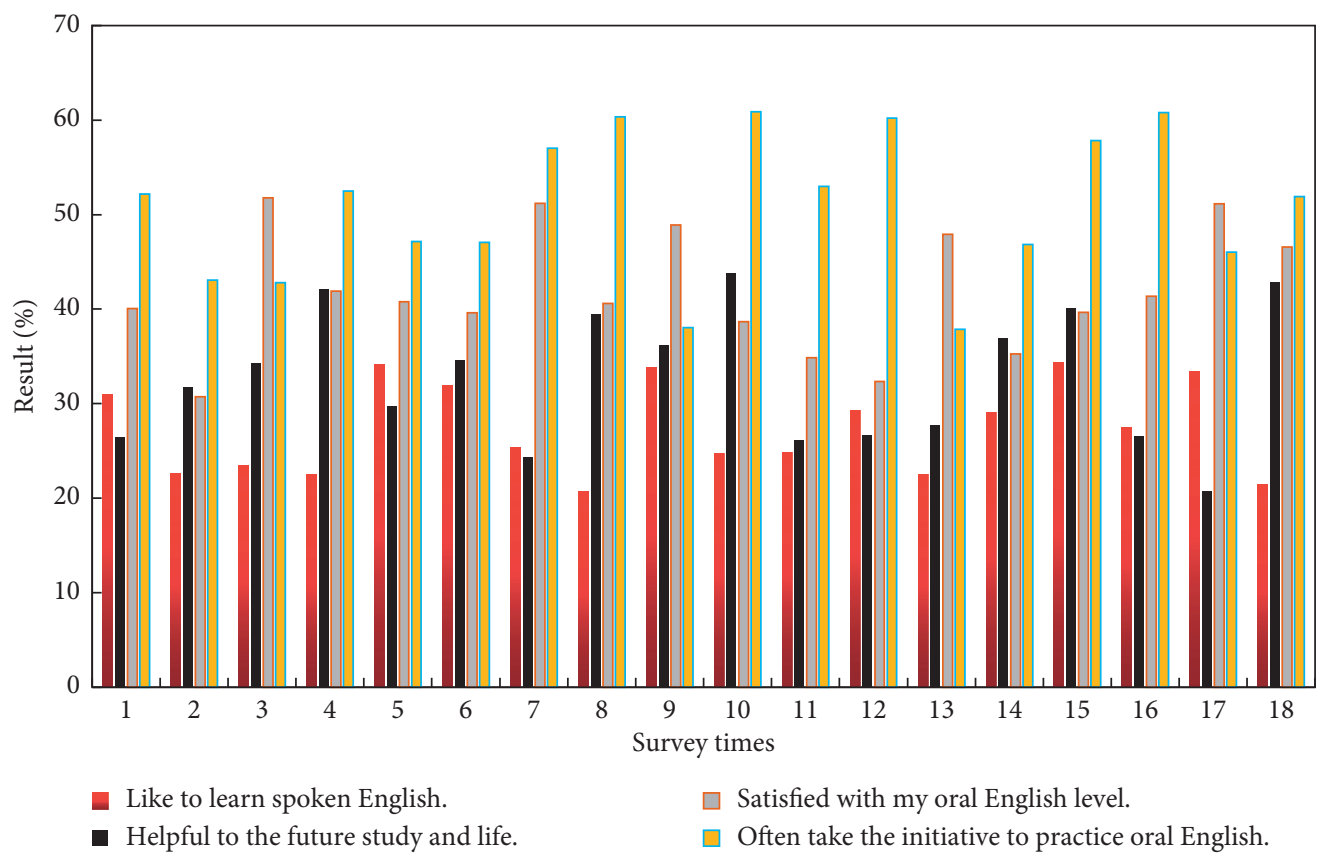

FIGURE 12: The result of the principal component analysis method.

principal component analysis method is used for the scale. The result of the principal component analysis method is shown in Figure 12.

The mean difference between the pretest and posttest in the experimental class was more obvious than that in the control class. The paired sample t-test results show that in the paired t-test of the pretest and the posttest, the oral learning interest of the experimental class is 6.514 , and the significance is 0 . The pre-test and post-test comparison of oral learning interest is shown in Figure 13.

In-depth analysis of the post-test questionnaire data of the experimental class found that most students pay more attention to oral English learning. $62.86 \%$ of the students like oral English. All the students under investigation are clear about the role and influence of oral English. Most of the students want to learn fluent English. The situation of students' satisfaction with the spoken language learning system is shown in Figure 14.

Investigating the teaching activities of the experimental process, it was found that most students are satisfied with the oral English teaching in a technologically rich environment, and really feel that the English classroom teaching in a technologically rich environment is good for their own oral expression and human-computer dialogue. It was helpful, and none of the students voted against it. The teaching activity evaluation survey is shown in Figure 15.

Table 13 shows the comparative changes before and after students choose roles. 


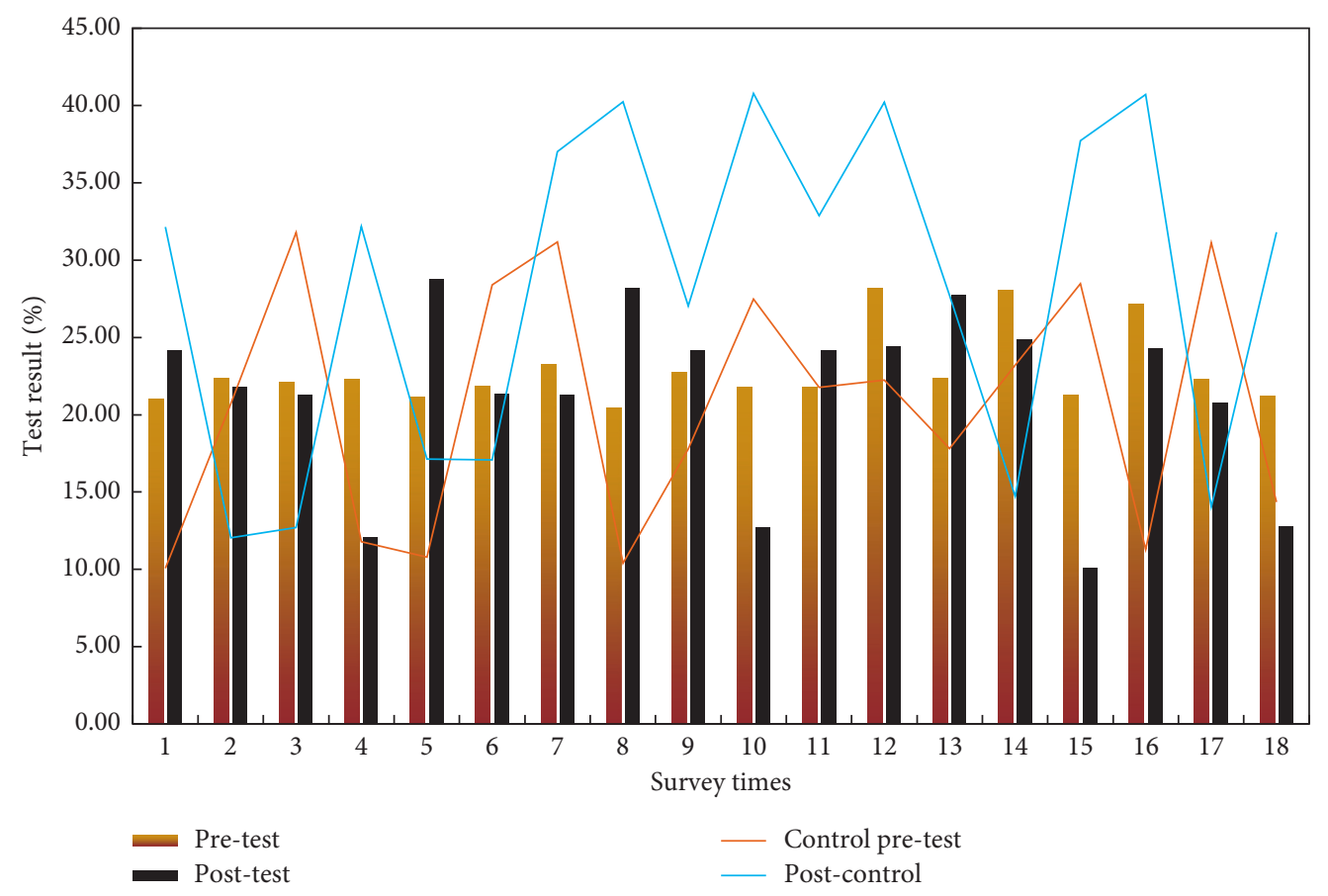

FIGURE 13: The pre-test and post-test comparison of oral learning interest.

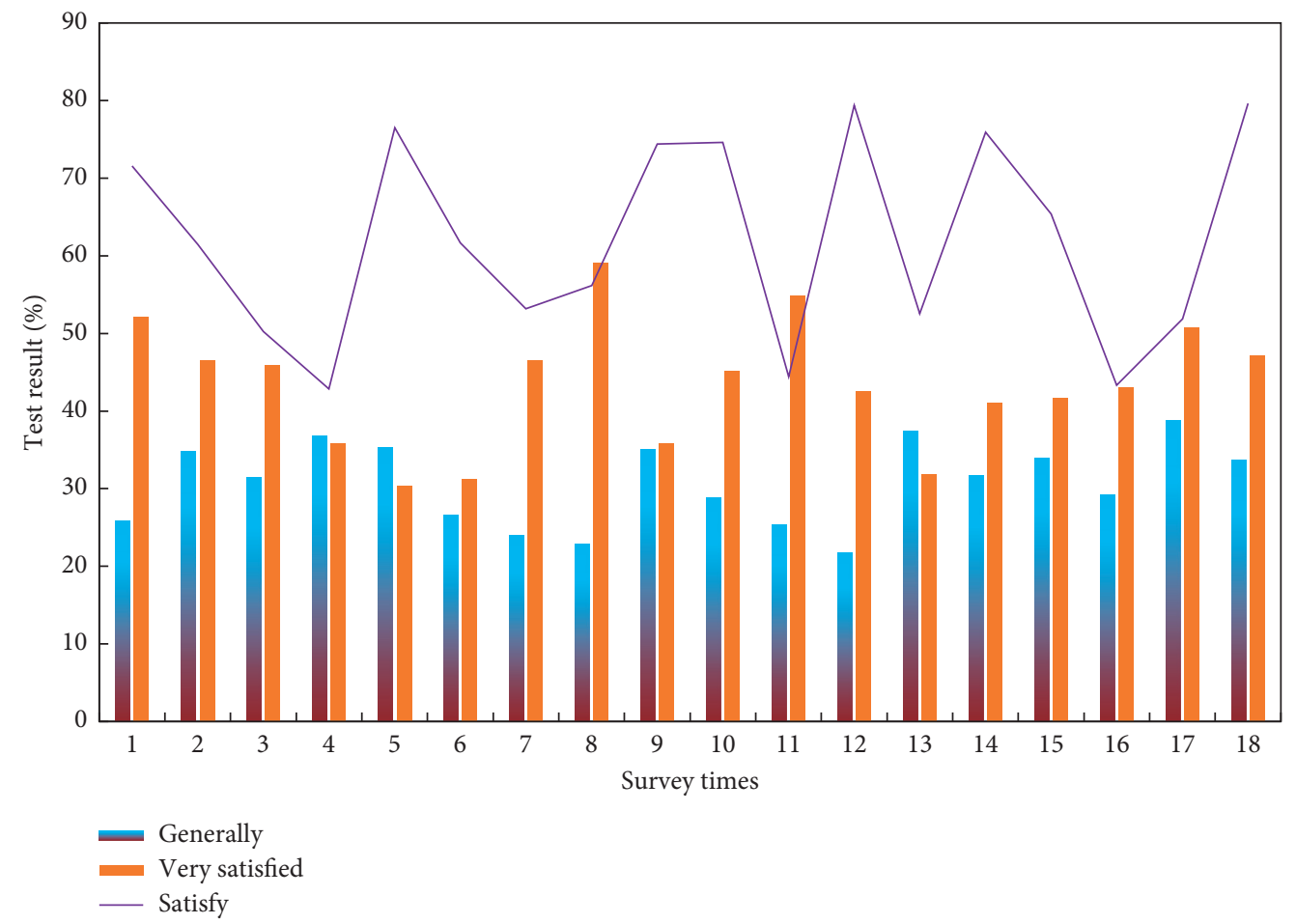

FIGURE 14: The situation of students' satisfaction with the spoken language learning system. 


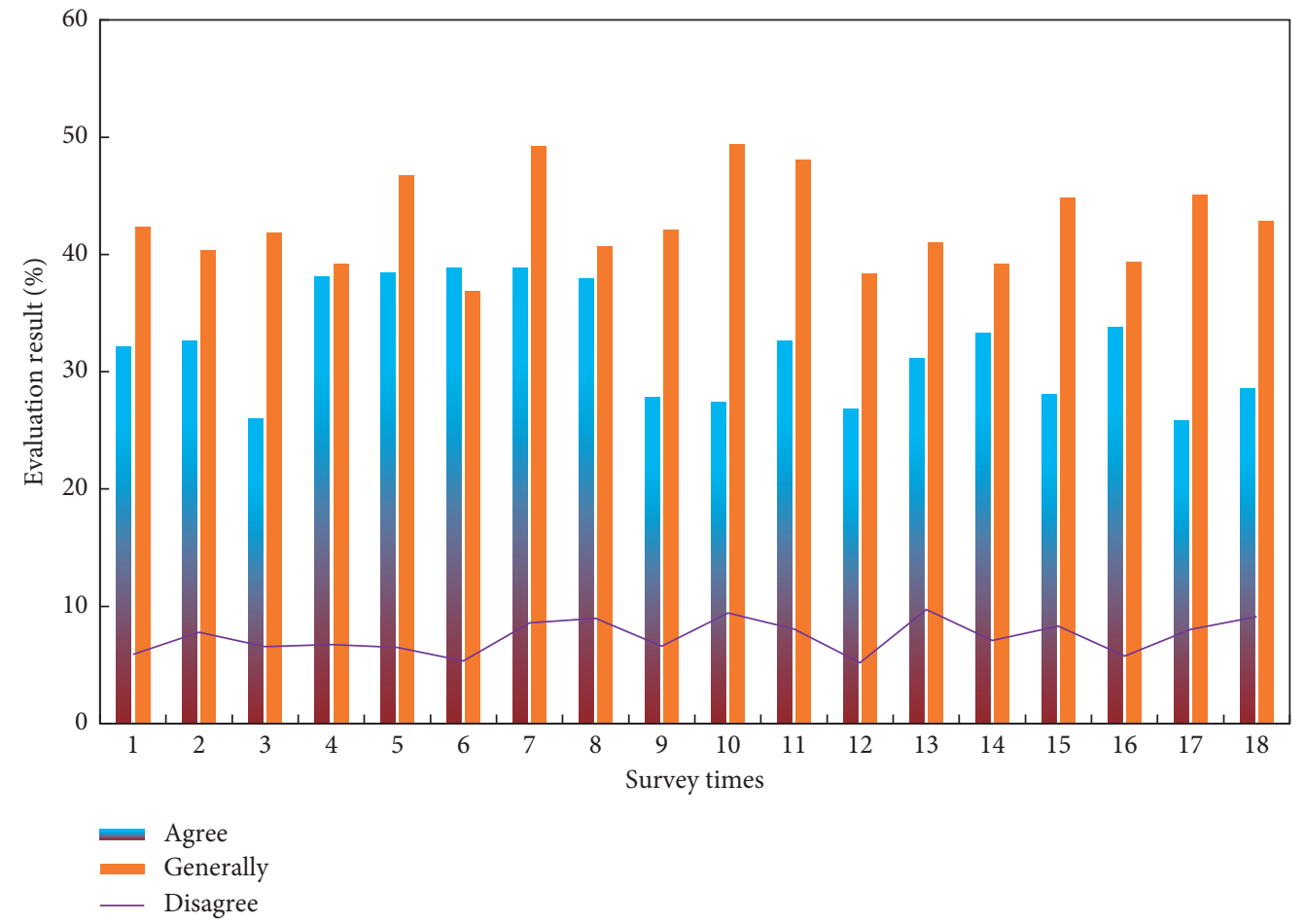

FIGURE 15: The teaching activity evaluation survey.

TABLE 13: Comparison of changes before and after students choose roles.

\begin{tabular}{lccc}
\hline $\begin{array}{l}\text { Serial } \\
\text { number }\end{array}$ & Role & Name & $\begin{array}{c}\text { Pre-test } \\
\text { self-assessment } \\
\text { score }\end{array}$ \\
\hline 1 & Journalist & Classmate a & 99 \\
2 & Passerby1 & Classmate b & 89.6 \\
3 & Passerby2 & Classmate c & 96.9 \\
4 & Passerby3 & Classmate d & 77.5 \\
5 & Passerby4 & Classmate e & 88.7 \\
\hline
\end{tabular}

\section{Conclusions}

(1) The focus of this article is hardware circuit design and experimental design of functional modules. The method focuses more on practical operation and download verification, and encourages innovation based on experiments.

(2) Under the guidance of the teacher, the students describe, explain (report), and respond to the cultural knowledge and cultural awareness. Over time, through repeated contact and explicit reference to cultural learning models, students gained more knowledge about the target culture, developed more appropriate language and cultural behavior, gained more understanding, and enhanced Awareness of oneself and other cultures and abilities. As a cultural learner, the final result will vary depending on the student's learning environment and teaching methods.

(3) Although processor-based approaches are becoming more common in China, this paper specifically examines their impact on improving intercultural communicative competence. This will help improve culture teaching across the country and promote the development of a new generation of college students who not only improve their English but also enhance their intercultural communicative competence.

\section{Data Availability}

This article does not cover data research. No data were used to support this study.

\section{Conflicts of Interest}

The authors declare that they have no conflicts of interest.

\section{References}

[1] M. East, "Research into practice: the task-based approach to instructed second language acquisition," Language Teaching, vol. 50, no. 3, pp. 412-424, 2017.

[2] Y. Setty and O. Salzman, "A methodological, task-based approach to procedure-specific simulations training," International Journal of Computer Assisted Radiology and Surgery, vol. 11, no. 12, pp. 2317-2324, 2016.

[3] S. Dai, "An exploration of task-based approach to making Chinese learnable: a teacher-research action project," Transactions of the American Ophthalmological Society, vol. 14, no. 1, pp. 364-370, 2015.

[4] S. M. H. Hosseini, M. Pritchard-Berman, N. Sosa, A. Ceja, and S. R. Kesler, "Task-based neurofeedback training: a novel approach toward training executive functions," NeuroImage, vol. 134, pp. 153-159, 2016.

[5] M. H. Chou, "A task-based language teaching approach to developing metacognitive strategies for listening 
comprehension," International Journal of Listening, vol. 31, no. 5, pp. 1-20, 2017.

[6] N. V. Baryshnikov, "Cultural transformation in the Linguadidactical dimension," Procedia-Social and Behavioral Sciences, vol. 200, pp. 87-91, 2015.

[7] T. Copeland, "Teaching the research process through student engagement: cultural consensus analysis of HIV/AIDS," Annals of Anthropological Practice, vol. 40, no. 2, pp. 148-163, 2016.

[8] M. Lewicka and A. Waszau, "Cultural competence in teaching Arabic as a foreign language," Universal Journal of Educational Research, vol. 4, no. 12, pp. 2750-2760, 2016.

[9] M. Catalo, N. Antheaume, and H. Ismail, "Transferring methods to teach business administration from one cultural context to another," Future Business Journal, vol. 1, no. 1-2, pp. 51-64, 2015.

[10] S. Greenwood and K. Fyers, "Epistemological development in first-year nursing students undertaking cultural safety education," Journal of Nursing Education, vol. 57, no. 4, p. 229, 2018.

[11] R. Chi and D. Suthers, "Assessing intercultural communication competence as a relational construct using social network analysis," International Journal of Intercultural Relations, vol. 48, pp. 108-119, 2015.

[12] L. Cavalheiro, "Developing intercultural communicative competence in ELF communication," Elope, vol. 12, no. 1, p. $49,2015$.

[13] N. O. García, M. F. D. Velásquez, C. A. T. Romero, and J. H. O. Monedero, "Remote academic platforms in times of a pandemic," International Journal of Emerging Technologies in Learning, vol. 16, no. 21, pp. 121-131, 2021.

[14] T. R. Tili and G. G. Barker, "Communication in intercultural marriages: managing cultural differences and conflicts," Southern Communication Journal, vol. 80, no. 3, pp. 189-210, 2015.

[15] M. J. Collier, "Intercultural communication competence: continuing challenges and critical directions," International Journal of Intercultural Relations, vol. 48, pp. 9-11, 2015.

[16] C. Sun, "The cultivation of cross-cultural communication competence in oral English teaching practice," English Language Teaching, vol. 8, no. 12, p. 7, 2015.

[17] T. Hao and Y. Zhang, "An investigation of Chinese students' acquisition of oral and written English through the measurement of processability theory," International Journal of Applied Linguistics \& English Literature, vol. 4, no. 2, pp. 207-212, 2015.

[18] D. Bruner, S. Kemtong, and B. Radic-Bojanic, "EFL oral communication teaching practices: a close look at university teachers and A2 students' perspectives in Thailand and a critical eye from Serbia," English Language Teaching, vol. 8, no. 1, pp. 11-20, 2015.

[19] H. Zhu, H. wei, B. Li, X. Yuan, and N. Kehtarnavaz, "Realtime moving object detection in high resolution video sensing," Sensors, vol. 20, no. 12, 2020.

[20] H. Wei and N. Kehtarnavaz, "Determining number of speakers from single microphone speech signals by multilabel convolutional neural network," in Proceedings of the IECON 2018-44th Annual Conference of the IEEE Industrial Electronics Society, IEEE, Washington, DC, USA, October 2018.

[21] S. Baldi, M. Nunzi, and C. D. Brina, "Efficacy of a task-based training approach in the rehabilitation of three children with poor handwriting quality: a pilot study," Perceptual \& Motor Skills, vol. 120, no. 1, p. 323, 2015.
[22] Z. Ni and J. Liu, "An empirical study on task-based listening teaching mode in junior high school of China," Advances in Language and Literary Studies, vol. 8, no. 2, p. 202, 2017.

[23] A. Abdellah and A. Haridy, "Medieval Muslim thinkers on foreign language pedagogy: the case of Ibn Khaldun," Journal of Linguistics, vol. 193, pp. 62-71, 2017. 